\title{
O tempo de Hawking
}

\author{
Henrique Fleming
}

Os grandes criadores da ciência não conhecem a glória do sucesso através de suas obras de real mérito cientffico. Apesar dos esforços e da perseverante catequese de pedagogos como Robert Hutchins, Mortimer J. Adler, Gerald Holton, temos que reconhecer que a leitura dos clássicos da ciência reserva suas delícias para poucos eleitos. Qualquer coleção de clássicos, como os Great Books da Encyclopaedia Britannica, serve para exemplificar. Do lado humanistico a série apresenta livros de leitura gostosíssima, como Rabelais, Tolstoi, Homero, o Moby Dick, até Platão e Kant... o lado cientffico, Euclides (Os elementos), Ptolomeu (O Almagesto), Galeno: leituras que exigem toda a disciplina que nos tenha sobrado dos bancos escolares. Há exceções, como Galileu, que escreveu em magnffico italiano e é hoje considerado um clássico da língua. $O$ problema se agrava com o aguçar-se da especialização. As obras cientfficas tornam-se ilegíveis, e os físicos que buscam atingir o público devem escrever, além de seus textos acadêmicos, obras de outro tipo. Alguns alcançam sucesso, como Faraday com The Chemical History of a Candle. Outros, um triunfal insucesso, como Lord Kelvin e P.G. Tait, com o Treatise on Natural Philosophy, que resultou ser inacessivel para o público, mas um sucesso para os especialistas (tratou-se de um erro de pontaria). A maioria fracassa redondamente. A literatura física, mesmo a de divulgação, tinha, de qualquer forma, um público relativamente restrito: os próprios ffsicos, outros acadêmicos e os que Steven Weinberg chamou de intelligent attorneys, profissionais de nivel intelectual elevado.

Em 1919 a física teórica, pela primeira vez, ganha as manchetes da grande imprensa: é anunciada no Times de Londres a confirmação experimental da teoria da relatividade geral, e, conseqüência clamorosa, a derrubada da teoria newtoniana da gravitação, sólida rocha que escorava tudo o que se sabia sobre a física do espaço. Havia clima propício para tanto: A Grande Guerra terminara havia pouco, e a ânsia por uma retomada do relacionamento normal entre os povos aproveitou-se desse triunfo cientffico que exigira uma verdadeira colaboração internacional, envolvendo um alemão, Einstein, um inglês, Eddington, e até brasileiros, pois a medida física crucial, que necessitava de um eclipse solar, encontrava condições otimas para observação em Sobral, Ceará, e na ilha do Príncipe, na África. O grande herơi é Einstein, que alcança a notoriedade que lhe pesará sobre os ombros até o fim da vida. (E a urucubaca já rondava o Brasil: choveu o dia inteiro em Sobral, e os dados relevantes foram todos colhidos em Príncipe.) De um dia para o outro a teoria da relatividade virou moda, e todo físico moderadamente alfabetizado tentou explicá-la aos leigos, para não falar dos próprios leigos, que, sem entendê-la, esperavam poder explicá-la aos seus pares. Surgiram livros com titulos curiosos, como o de um certo Lincoln Barnett, jornalista, chamado O Universo e o dr. Einstein, como se o próprio Universo, posto ao lado do seu decifrador, intimidado, devesse manter o tratamento respeitoso. Prêmios foram criados para quem conseguisse explicar a Relatividade em um número limitado (e preciso!) de palavras. Foi um grande sucesso, e daquela vez não houve exagero, pois, conscientemente ou não, comemorava-se ali um dos maiores feitos da história da inteligência humana.

Quando a descoberta é realmente grande, a intuição de sua importância não é mais privilégio da minoria iniciada. Quando se aprende alguma coisa nova sobre o tempo e o espaço, o 
homem comum pressente a sacralidade do momento e tira o seu chapéu. Ao longo de milhões de anos de evolução desenvolvemos, a partir de nossos sentidos e com o fim precípuo de sobreviver, nossos conceitos espaço-temporais. Era um problema importante, a sobrevivência, e não um exercício acadêmico: por isso os conceitos que ali se formaram são tão sólidos e parecem tão inevitáveis; por isso os defendemos tão arduamente. Mas basta algum raciocínio para nos convencermos de que a origem utilitária desses conceitos aponta ela mesma para as suas limitações. Será esse tempo tão empiricamente construído transportável para situações radicalmente diferentes?

A primeira dessas situações foi identificada por Einstein: o homem nunca se movera com velocidades próximas à velocidade da luz (e, de fato, continua não tendo se movido, mas está para fazê-lo logo). A teoria da relatividade estende o nosso conceito de tempo para essa nova situação, mas, ao estendê-lo, modifica-o, e a ferida é funda. A grandeza do homem está nisto: pouco Ihe importa que Ihe sejam de pouca valia, para escapar de seus inimigos, as correções relativísticas à sua idéia utilitária de tempo. A descoberta de que o tempo não é mais o que o acompanhou por toda a infância, comove-o profundamente.

Este tema, o espaço e o tempo, inaugura então a era da grande divulgação das descobertas da física. Outros assuntos entrarão em cena, motivados diferentemente (a bomba atômi$\mathrm{ca}$, os foguetes, o "raio" laser), mas os impactos realmente grandes precisam de algo mais do que uma bravata tecnológica.

Em tempos recentes, dois livros, cujos autores são físicos famosos, alcançam grande sucesso de vendas: o primeiro, cronologicamente, é a pequena jóia de Steven Weinberg, The First Three Minutes, um relato primoroso, para "advogados inteligentes", da cosmologia contemporânea; o segundo, um extraordinário livro de memórias de Richard P. Feynman, intitulado Surely You're Joking, Mr. Feynman. Mr. Feynman permanece nos primeiros lugares da lista de best sellers do New York Tirnes por vários meses. Desde então o assédio aos autores em potencial, por parte das grandes casas editoras, é constante, e resistir à tentação começa a ficar diffcil. O tema mais tentador continua sendo o espaço e o tempo. Alvo principal do assédio: o herdeiro de Einstein.

Há uns três ou quatro anos a imprensa descobriu Stephen W. Hawking, professor da Universidade de Cambridge, onde ocupa a cátedra de maior prestígio do mundo, a que foi de Isaac Newton. O título é Lucasian Professor. Antes de Hawking pertenceu a outro monstro sagrado da história da física, Paul Adrien Maurice Dirac, um dos criadores da mecânica quântica e descobridor da antimatéria, na minha opinião o maior f́sico deste século depois de Einstein. Hawking é um brilhante ffsico teórico cujas pesquisas versam sobre a teoria da gravitação. $\mathrm{O}$ que $\mathrm{o}$ coloca em posição absolutamente singular é sua tragédia pessoal. Atingido por uma grave doença degenerativa, está atualmente quase totalmente paralisado, capaz apenas de mover ligeiramente alguns dedos. Há dois anos atrás era ainda capaz de falar, se bem que poucos o entendessem. Hoje, utiliza-se de um computador que pronuncia as palavras selecionadas de uma tela, controlada com os únicos movimentos que é capaz de executar, com as pontas dos dedos. Continua trabalhando intensamente e produzindo jóias da física teórica. Sua excelência cientifica, sua dramática vida e o furor da imprensa o tornaram uma figura mundial, o cientista mais conhecido desde Einstein. Seu livro, Uma breve história do tempo, era inevitável.

A melhor descrição breve do livro encontra-se na introdução escrita por Carl Sagan: "Ai estão revelações lúcidas sobre os domínios da física, astronomia, cosmologia e coragem".

De onde surgiu o Universo? Como e por que ele começou? Chegaria a um fim e, nesse caso, como seria ele?

Essas perguntas, já nos primeiros parágrafos do texto, anunciam, quem tiver ouvidos que ouça, que a obra tratará da gravitação quântica. Eis o porquê.

Em sua primeira série de trabalhos, que já lhe haveriam de granjear fama e uma sólida reputação entre os físicos, Hawking demonstrou que, dentro da teoria de Einstein, não se pode entender a origem do Universo. É preciso explicar tudo issó. A teoria de Einstein, comumente chamada de relatividade geral, pertence à fĺsica clássica, isto é, a física que não é quântica. Não se trata de um mero jogo de palavras, ou de uma classificação do tipo que se usa em literatura (Simbolismo, Realismo, etc.). A física clássica e a física quântica são descrições da natureza profundamente diferentes, e diferentes em essência. Qual é a diferença fundamental entre as duas concepções do mundo? Na física clássica, uma partícula que viaja de um ponto a outro descreve uma trajetória perfeitamente definida. Em cada ponto dessa trajetória, a partícula tem uma posição e uma velocidade que podemos determinar com a precisão que nos aprouver. $\mathrm{Na}$ fĺsica quântica, sequer existe o conceito de trajetória (esta é uma das maneiras de formular o "princípio da incerteza"). Em nenhum ponto é possível conhecer simultaneamente a posição e a velocidade da parti- 
cula, a não ser de uma maneira grosseira, estipulada pelo princípio de incerteza. Num certo sentido, isto equivale a dizer que todas as curvas que ligam os dois pontos extremos têm igual direito de serem chamadas trajetórias: o movimento é uma espécie de média entre todas as "trajetórias". A decisão entre a física clássica e a física quântica não é uma escolha que se possa fazer: é determinada pela experiência, e a natureza é bem clara ao declarar-se quântica e não clássica. Para os sistemas físicos que estudamos no dia-a-dia, como a maioria dos corpos macroscópicos, a ffsica clássica é perfeitamente aplicável, já que, nesses casos, conduz aos mesmos resultados que a física quântica. A descrição quântica do movimento da Terra em torno do Sol é muito diferente da clássica, mas os resultados são os mesmos. Já para os átomos, e para sistemas macroscópicos muito especiais, como superfluidos e supercondutores, a f́sica clássica fracassa totalmente, enquanto que a física quântica fornece uma descrição coerente e quantitativamente exata. Pois bem, Hawking demonstrou que, se olharmos para trás na evolução do Universo, chegaremos inevitavelmente a um momento em que a teoria (clássica) de Einstein perde o sentido, e começam a aparecer densidades de energia infinitas e toda a sorte de monstros incontroláveis. Se falha a teoria clássica, isto é normalmente um sinal de que é necessário usar a teoria verdadeira, a quântica, da qual a clássica é uma mera aproximação. Assim, praticamente desde seus primeiros trabalhos, a sorte estava lançada, e o caminho para a gravitação quântica era sem retorno.

Do seu segundo grupo de trabalhos, emerge o que considero ser o mais importante resultado obtido até hoje da combinação entre a relatividade geral e a mecânica quântica. Trata-se da descoberta de que um buraco negro não só absorve tudo o que se aproxima dele, mas também emite radiação. É uma conseqüência do princípio da incerteza de Heisenberg. Na mecânica quântica, um carro em uma garagem fechada tem uma probabilidade (ínfima, mas não nula) de atravessar a porta fechada e aparecer do outro lado. $O$ decaimento alfa de certos núcleos é uma manifestação desses fenômenos, que são impossíveis na mecânica clássica. Numa grande exibição de coragem, uma das virtudes capitais dos grandes físicos teóricos, Hawking utilizou o princípio da incerteza no domínio da gravitação e chegou ao resultado fundamental, que diz que, via tunelamento quântico, sempre escapa alguma coisa de dentro do buraco negro, de forma análoga ao atravessamento da porta da garagem que mencionei acima. Motivado por idéias do físico israelense Bekenstein, mostrou depois que a radiação emitida por um buraco negro possui uma temperatura bem definida, o que permitiu uma extensão da termodinâmica clássica à física desses objetos astronômicos, ao mesmo tempo em que se constituiu em um grande progresso da própria termodinâmica, tida como uma área da física em que nada mais poderia acontecer de fundamental. Este assunto é tratado no capitulo intitulado Black Holes Ain't So Black. O passo seguinte seria tratar também o campo gravitacional como um sistema quântico, e esse era, seguramente, o objetivo principal de Hawking. Antes de lá chegar, porém, ele mediria de novo forças com a cosmologia, sob um outro aspecto.

O Universo é curvo, como a superfície de um balão inflado. Se tomarmos $1 \mathrm{~cm}^{2} \mathrm{da}$ superfície do balão e nos restringirmos a observações feitas ali, será muito fácil de detectar a curvatura do balão quando ele ainda estiver pequeno; quando, muito inflado, tiver metros de diâmetro, $0 \mathrm{~cm}^{2}$ que escolhemos será praticamente plano. Há muitas maneiras de estimar a idade do Universo, isto é, o tempo que decorreu desde o Big Bang. Pois bem, o Universo é jovem demais para que a parte dele que observamos (o nosso " $\mathrm{cm}^{2 n}$ ) seja tão plano como nos parece. Essa motivação e outras, ligadas a problemas com a física das partículas elementares, levaram Allan Guth, do Massachusetts Institute of Technology, e A. Starobinskii, da União Soviética, a propor que, em certo momento da evolução do Universo, a expansão se deu vertiginosamente, talvez à máxima velocidade permitida, de maneira que o Universo teve seu raio multiplicado por um número descomunal em uma fração de segundo. Isto põe as coisas no lugar, ao preço de se modificar a história monótona do Universo, pela inclusão de um breve mas decisivo momento de fantástica atividade. Chama-se o modelo inflacionário. O terceiro grupo de trabalhos de Hawking consiste em um estudo detalhado da exeqüibilidade deste modelo. De partida mostrou que a forma proposta por Guth, em seus detalhes, era impossível, pois geraria inevitavelmente um universo excessivamente granuloso, entrecortado por um número enorme de paredes, em contradição com a isotropia e a homogeneidade observadas, em boa aproximação, experimentalmente. Um mecanismo proposto pelo brilhante físico soviético $\mathrm{A}$. Linde salva o modelo, mas a um preço que muitos físicos relutam em pagar: certas propriedades dinâmicas do modelo teriam que ser determinadas com uma precisão muittssimo elevada, para que, hoje, pudéssemos ter o que temos. Em outras palavras, uma alteração infinitesimal no que aconteceu no período inflacionário teria conduzido a um universo totalmente diferente do que temos hoje.

No trecho do livro em que discute esses assuntos, Hawking exibe aspectos de sua personalidade provavelmente inesperados para aqueles que continuam, mesmo em nossa era 
iconoclasta, a pensar que um cientista está mais para anjo do que para homem. Depois de ter estado em Moscou e de discutir com Linde, tomando conhecimento das idéias do físico soviético para "salvar" o modelo inflacionário (o que viria a ser chamado de "nova inflação"), Hawking passou pelos Estados Unidos e deu um seminário na Universidade Drexel, em Philadelphia, durante o qual mencionou o trabalho do colega russo. Conta que, após o seminário, foi procurado por um jovem físico, Paul Steinhardt, que Ihe fez muitas perguntas detalhadas. Surpreendeu-se pouco depois ao deparar com um artigo, de Steinhardt e seu estudante Andreas Albrecht, em que as idéias ouvidas no seminário eram expostas como próprias, sem menção de seu verdadeiro autor. Considerando-se que Steinhardt tornou-se um ff́sico famoso por essa sua "descoberta", a denúncia de Hawking deve ter causado escândalo nos meios cientificos, principalmente americanos, e contribuído para aumentar a antipatia que certos setores da ciência americana devotam a ele. É digno de nota que essa acusação de plágio tenha sido omitida nas reimpressões mais recentes do livro. Mais sobre essa antipatia abaixo. Por enquanto quero ressaltar que Hawking, quando atira, usa chumbo grosso. No fim do livro seu alvo é nada menos do que Isaac Newton, seu mais ilustre antecessor na cadeira lucasiana ou onde quer que se tenha sentado. Hawking não quer deixar pedra sobre pedra, e investe sobre o grande mito com uma acusação das piores, a de ter, no exercício de seu cargo de diretor da Casa da Moeda, decretado o énforcamento de muitos homens, por falsificação de dinheiro.

Há alguns anos Hawking publicou um opúsculo intitulado Is the end in sight for theoretical physics? (Estará mesmo à vista o fim - por falta de problemas fundamentais - da física teórica?). O autor está propenso a responder que sim. Vejamos sua argumentação. Incontáveis vezes no passado, luminares da ciência enlamearam sua reputação ao predizer erroneamente o fim da física. Por isso, quando alguém se aventura a correr de novo o risco, deve ter muito boas razões. As de Hawking são tentadoras. Em nossa época, pela primeira vez, o estudo do mundo microscópico levou a conclusões importantes sobre o mais macroscópico dos sistemas, o Universo como um todo. Fechou-se um ciclo fundamental: o microcosmo influenciando o macrocosmo e reciprocamente. Ora, é de se esperar que isso signifique que a descrição do microcosmo tenha atingido um nivel muito fundamental, e é necessário, por consistência, supor que também a descrição do Universo esteja sendo feita em nivel fundamental. Em poucas palavras, essa é a motivação de Hawking. Em conseqüência, todas ou quase todas as descobertas importantes já teriam sido feitas.

A tese caiu, nos meios cientificos americanos, como uma bomba, talvez por ter prejudicado o lobby para o financiamento de novos grandes projetos para a f́sica. Uma das respostas a ela veio do grande físico da matéria condensada, P.W. Anderson, prêmio Nobel em 1977, e foi de truculenta para baixo. Hawking é chamado, desdenhosamente, de théoricien de cabinet, numa exibição de mau gosto que me causou calafrios, quando a li. $\mathrm{O}$ que mais poderia ser um homem que só move a ponta de alguns dedos? Suas opiniões ousadas e sua relativa inacessibilidade, potenciadas pelo alarde da imprensa ao seu redor, engendraram, como disse acima, em alguns meios, uma certa antipatia, ou pelo menos impaciência, a seu respeito. O surpreendente estilo cortante que utiliza em suas anedotas científico-sociais pode ser o único troco que the é possível dar.

Temos que abordar agora o quarto grupo dos seus trabalhos, ao qual pertencem as pesquisas que realiza neste momento. Tratam do grande problema da física teórica atual (ao menos do ponto de vista dos théoriciens de cabinet): a amalgamação da relatividade geral com a mecânica quântica.

Sabe-se pouquíssimo sobre a gravitação quântica, porque quase não se tem informações a respeito de como são os campos gravitacionais a altas freqüências, isto é, as ondas gravitacionais. Não somos ainda capazes de detectá-las, e muito menos de produzi-las. De fato, até há pouco muitos duvidavam da existência delas (preditas que foram pela teoria de Einstein) e, por isso, também da existência de uma gravitação quântica. Foi a observação detalhada do pulsar binário PSR-1913 16, descoberto por Hulse e Taylor em 1974, que permitiu obter sinais indiretos, mas muito seguros, da existência de ondas gravitacionais: a descrição einsteiniana dessa estrela dupla prevê, devido à emissão dessas ondas, uma diminuição gradativa, detalhadamente calculada, da distância média entre os dois componentes do sistema binário, e essa diminuição é observada com muito boa precisão. Temos, então, que construir uma gravitação quântica. Felizmente dispõe-se, para isso, de prescrições muito gerais, descobertas pelo genial Richard P. Feynman, de quem já falamos acima. É preciso fazer uma "soma sobre histórias", onde cada "história" é um possível comportamento do sistema no sentido da física clássica. Já mencionamos, como exemplo, a trajetória de uma partícula: na física clássica a trajetória é única; na física quântica, todas as curvas ligando o ponto de partida ao ponto de chegada contribuem. Cada "trajetória" dessas é um 
exemplo do que estamos chamando de "história". Na física clássica há uma história bem definida; na quântica, o comportamento do sistema depende da soma sobre todas as histórias, num sentido preciso, intuído por Feynman. A gravitação quântica envolve então uma soma sobre histórias, que é fantasticamente mais complicada do que o caso da mecânica do ponto, que usamos para exemplificar o método.

A soma sobre histórias que nos interessa envolve uma área da matemática ainda em construção (a integração em espaços cujos elementos são funções), de maneira que às dificuldades com os conceitos físicos sobrepõem-se dificuldades matemáticas. É neste ponto que Hawking propõe a idéia mais ousada e mais bonita do livro. Se o tempo fosse um número imaginário (é um termo técnico: o quadrado de um número imaginário é negativo; eles não são mais imaginários do que os outros), seria possível realizar a soma, uma vez que se cairia em uma matemática conhecida, as integrais de Wiener. $\mathrm{D}$ Universo que então se obtém é de estarrecedora simplicidade, sem começo, sem fim, sem singularidades e sem limites espaciais (é um universo circunavegável). Eis a idéia de Hawking: o tempo "real" é esse tempo imaginário. O tempo que não é imaginário é simples aparência e reflete nossos hábitos milenares, dissociados de análises em escala cosmológica (Na matemática existem os números reais, de quadrados positivos, e os números imaginários. Para um matemático, então, Hawking diz que o tempo imaginário é o real, e o real é imaginário, um aforismo cosmológico.). Assim, curiosamente, o problema criado pelo importante trabalho de Hawking de descoberta das singularidades na física clássica é resolvido pela análise mais profunda da física quântica: desaparecem as singularidades, e desaparece a inevitabilidade do começo do Universo e do começo do tempo. É preciso, porém, que se diga que esta parte de sua obra é de caráter muito mais especulativo do que as anteriores, o que é inevitável dada a escassez de resultados experimentais sobre a gravitação quântica. Por outro lado, a beleza da idéia e dos resultados Ihes dá uma força quase irresistível. A ff́sica aqui está muito próxima da poesia.

Estamos nos aproximando do fim do livro. Hawking falará ainda da "flecha" do tempo (na realidade identifica três) e da teoria das supercordas, que é o que se acredita ser o melhor candidato a uma "teoria de tudo". O volume termina com um capftulo intitulado Conclusão, que excluo desses comentários para não prejudicar o prazer de sua leitura, e com três breves biografias, de Einstein, Galileu e Newton. Um Glossário explica o significado dos termos técnicos que aparecem, raramente, no texto.

Para encerrar, alguns comentários gerais. Um vilão percorre todo o livro, o Princípio Antrópico. É como se ele tivesse sido escrito para mostrar que se pode explicar o Universo sem o uso desse "Princípio". Mas o Princípio Antrópico nada explica. Seria explicar o Universo descobrir que todos os seus parâmetros são determinados completamente pelo requisito de que, em nossa época, os siris devem andar para trás? Qualquer fenômeno suficientemente complicado de nossos dias, que envolva, por exemplo, seres vivos, é equivalente nesse sentido. $O$ encanto do Princípio Antrópico mede, na realidade, a alta conta em que nos temos. Estou certo de que o autor também pensa assim, e convencido de que se utilizou dele para "costurar" os vários capftulos para que formassem a unidade desse notável livro.

Hawking possui um estilo limpíssimo, muito claro e conciso, dando às vezes a sensação de que não é possivel escrever certas frases de outra forma. Faço-lhe o cumprimento máximo: quando trata de temas muito sutis, chega a lembrar Santo Agostinho. Mas afinal, como diria Platão, escrever bem é escrever do que se entende!

Como ler o Brief History? O autor seguiu o ditame de que um livro de ciência tem que ser também um livro, e um livro se lê do começo ao fim, de enfiada. Isto resultou de uma escolha bem definida. Dois grandes livros de divulgação recentes podem ser usados para esclarecer a questão: The First Three Minutes, de Steven Weinberg, e QED: The Strange Theory of Light and Matter, de Richard P. Feynman. São livros que resultam de intenções bem diferentes das de Hawking. Weinberg e Feynman resolveram escrever autênticos livros de física teórica para leigos dispostos a algum esforço (que às vezes resulta ser muito esforço). Em contrapartida, fornecem, aos seus leitores, legtimos instrumentos de obtenção de conhecimento. No caso de Weinberg, aprende-se que muito da cosmologia pode ser entendido, até quantitativamente, com a versão quase-newtoniana da cosmologia, que usa apenas matemática do colegial; no de Feynman, uma engenhosa maneira de simular as regras quânticas de combinação de amplitudes de probabilidade permite descrever semiquantitativamente muitos fenômenos óticos e eletromagnéticos que escapam à física clássica, usando, de novo, apenas conhecimentos que se aprendem no colégio. Esses autores reconstruíram a teoria extirpando dela toda a matemática avançada, mantendo quase toda a física e aumentando significativamente o universo de leitores. Hawking escolheu outra estrada: nenhuma matemática, qualquer leitor. Que obteve sucesso, é ocioso dizer. Mas é preciso deixar claro que não o obteve através de concessões, já que não deixa fora de sua descrição ne- 
nhuma idéia fundamental e, felizmente, evita simplificações grosseiras e um certo tipo de metáfora, muito em moda nos jornais, que é um franco desrespeito à inteligência do leitor comum. Na ausência de reais demonstrações, a narrativa se apóia na força das imagens para adquirir a beleza misteriosa de um mito, valorizado pela narração de um dos seus criadores em pessoa.

A tradução é execrável e arruína completamente o esforço do autor. Eu, que sou do ramo, precisei adquirir a versão original para captar a beleza do livro. Em entrevista à Folha, a tradutora (que só agira até então no campo literário.) explica que não mais traduzirá obras científicas. Não deveria traduzir nada. Cumprimentos à editora Rocco, que resolveu refazer tudo. Espero que aceite um exemplar da primeira versão como pagamento da segunda. 